\title{
elyra
}

\section{António Aragão: Mais Exactamente Colagens?}

\section{Sara Lacerda Campino}

Faculdade de Ciências Sociais e Humanas (FCSH-UNL) - Instituto de Estudos de Literatura e Tradição (IELT)

Resumo: Este artigo propõe uma análise do livro Mais Exactamente $P(r) o(b l) e m a s$ (1968), escrito pelo poeta experimental português António Aragão, com base numa abordagem material que utiliza os conceitos de colagem, montagem e assemblagem.

Palavras-chave: António Aragão, Poesia Experimental, Colagem, Montagem, Assemblagem, Livro

Abstract: This paper proposes an analysis of the book Mais Exactamente $P(r) o(b /) e m a s$ (1968), written by the portuguese experimental poet António Aragão, based on material approach that uses the concepts of collage, montage and assemblage.

Keywords: António Aragão, Experimental Poetry, Collage, Montage, Assemblage, Book

Agora, ao contrário, as colagens e a série de objectos encontrados pretendem em especial potencializar-se, isto é, continuarem apenas como objectos, francamente objectos em relação uns aos outros. António Aragão, "Intervenção e Movimento" 
Em 1965, António Aragão publica um suplemento especial do Jornal do Fundão para divulgar as produções dos poetas experimentais, organizado em conjunto com E. M. de Melo e Castro, onde inclui também trabalhos da sua autoria, nomeadamente o artigo teórico intitulado "Intervenção e Movimento". Este texto incide sobre aquilo que Aragão designa como "arte do movimento", ou seja, um programa artístico que dinamiza as obras através da combinação de uma base matricial com a intervenção do acaso, recorrendo a uma estratégia de colagem capaz de potenciar objectos pré-existentes e de uso comum. A composição de poemas com pedaços de jornais é a técnica mais citada neste artigo como exemplo de pesquisa artística do movimento. Simultaneamente, são referidos vários autores e obras que o poeta considera relevantes, destacando-se Le Livre de Mallarmé como a mais notável, assim como alguns trabalhos de Raymond Queneau.

Três anos após a publicação do referido suplemento, Aragão dá à estampa a obra poética Mais Exactamente $P(r) o(b l) e m a s$ (1968), cuja orientação gráfica é também por si assumida. Aqui estão patentes as preocupações teóricas anteriormente enunciadas, nomeadamente através do modo como a utilização de processos de colagem permite realizar investigações em torno do formato do livro. Este será então o foco do presente ensaio para pensar a relação entre poesia e colagem a partir do estudo de uma obra de António Aragão.

A produção de livros concebidos como objecto artístico por António Aragão foi abordada recentemente por Catarina Figueiredo Cardoso na revista Cibertextualidades de 2015, dedicada à obra do poeta. A autora demonstra que, do ponto de vista da materialidade, os textos e imagens das publicações individuais de Aragão são pensados para o formato do livro e não apenas para a página (Cardoso 2015: 111). No que concerne ao livro Mais Exactamente $P(r) o(b /) e m a s$, Catarina Figueiredo Cardoso destaca os elementos excepcionais (tiras dobradas em papel colorido; formulários burocráticos; poemas encontrados em jornais; composição de imagens e texto manuscrito) naquilo que considera como uma publicação clássica de poesia com uma paginação simples. Por sua vez, Rogério Barbosa da Silva apresenta, no mesmo número da Cibertextualidades, uma "leitura crítica da poesia e do pensamento poético de António Aragão sob a perspectiva da invenção e liberdade de criação estética" (Silva 2015: 33), que encerra com uma análise demorada do 
referido livro de António Aragão, detendo-se igualmente em vários aspectos da sua composição e das suas eventuais relações (título; epígrafe; índice/estruturação; secções; texto; grafismo; citações; colagens; imagens; paginação; formatações; dobragens; materiais).

Para propor um modelo de análise dos processos compositivos presentes na obra Mais Exactamente $P(r) o(b /) e m a s$, é oportuno recuperar agora algumas definições que permitam distinguir diferentes técnicas subjacentes à colagem. Enquanto processo plástico, inicialmente explorado pelas vanguardas artísticas do início do séc. XX, a colagem consiste genericamente na junção de vários elementos pré-existentes, de origens diversas, num novo contexto. Se esse novo contexto for uma superfície, adotar-se-á a designação de colagem (ou collage), quando estiverem em causa relações de justaposição entre elementos estáticos, e de montagem (ou montage), quando essas mesmas relações forem de natureza temporal, implicando a ideia de movimento e/ou de sequenciação narrativa (Perloff 1998). No caso de se tratar da associação de elementos tridimensionais, poder-se-á utilizar a noção de assemblagem (ou assemblage), que por sua vez dirá respeito a um objecto encontrado (ou object-trouvé) quando se verificar que são apropriados objectos de produção industrial (Waldman 1992: 8).

\section{Assemblagem}

L'assemblage, par définition, est un acte qui consiste: à disposer des éléments et à les reunir pour former une totalité [...] C'est dans l'articulation entre "dispersion" et "rassemblement", entre libérté et ordre, que l'architecte en assemblant crée une architectonique, un "système": un ensemble organisé et "organique" avec des parties de natures différentes. Fondamentalement, c'est à travers cet acte instaurateur de "mettre ensemble" que s'énonce et s'inscrit la nature structurale de l'oeuvre. Pierre Litzler, "Architecture et Poétique de L'assemblage"

A perspectiva arquitectónica da assemblagem acima citada convoca vários termos que se podem encontrar imediatamente no formato de livro utilizado por Aragão em Mais Exactamente $P(r) o(b /) e m a s:$ reunião, totalidade, sistema, conjunto organizado, organicidade, partes diferentes, estrutura. Verifica-se, então, que entre os factores que constituem o livro enquanto sistema que forma uma totalidade convivem elementos disruptivos que abrem 
novas espacialidades dentro do mesmo (através do acto de desdobrar e dobrar os "P(r)o(bl)emas visíveis" ), justificando assim o recurso à ideia de assemblagem para poder pensá-los. É curioso constatar que logo na capa são anunciadas novas relações espaciais, possibilitadas pelo vazio elíptico que atravessa a palavra $p(r) o(b l) e m a s$ que consta no título, em concordância com os espaços abertos pelos parênteses que revelam os problemas dos poemas.

Para a clarificação da organização do livro contribuem a explicitação da sua estrutura, presente no índice, separadores e numeração de textos, assim como a definição de uma identidade própria para cada uma das partes que o compõem, diferenciando-se através das características materiais da paginação (tanto do suporte - tipo, cor, dimensões e dobragens do papel - como do seu arranjo gráfico) e das designações adoptadas em função da natureza

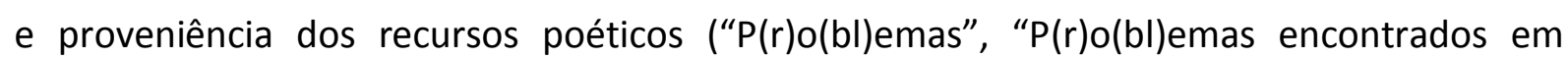
livros", "P(r)o(bl)emas encontrados em jornais" e "P(r)o(bl)emas visíveis (ao longo do livro)").

A categorização dos $p(r) o(b /) e m a s$ como encontrados remete de imediato para os objet-trouvés, o que implica conceptualmente uma ideia de espacialidade. No entanto, não é essa a vertente que interessa a António Aragão, mas sim a transposição para o texto das características identitárias de um objecto, na sua dimensão utilitária e liberta da transcendência (Aragão 1965: 52-54). Paralelamente, o facto de mais de metade dos poemas

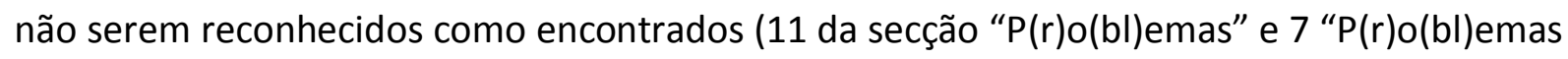
visíveis (ao longo do livro)" num total de 26) intensifica a curiosidade em relação à sua origem e processo de composição poética que tão claramente se assumem nos outros textos, adensando a vocação de problematização que está na génese desta obra.

De acordo com Rogério Barbosa da Silva, o título do livro e as designações das suas partes assumem-se como "exploração da linguagem enquanto uma problematização do poema" (Silva 2015: 39). No entanto, poder-se-á considerar também que o livro problematiza os mecanismos da colagem enquanto exploração das relações entre a escrita e a leitura, tanto no que diz respeito aos lugares das leituras onde o poeta encontra os seus poemas, como no que concerne aos lugares da escrita projectados pelo poeta para dar a conhecer os seus poemas encontrados, ou não, a outros leitores. 
A natureza espacial destes outros lugares instaurados pela orgânica do livro advém também da interferência entre várias partes distintas que, apesar de surgirem perfeitamente delimitadas no índice, funcionam no livro em sequências intercaladas, dado que os elementos que integram os "P(r)o(bl)emas visíveis" estão disseminados ao longo das restantes secções, localizando-se sempre entre dois poemas. Para além dos " $P(r) o(b l) e m a s$ visíveis" serem fisicamente distintos e convocarem espaços próprios, a sua inserção interrompe a continuidade das referidas secções através de sobreposições, desdobramentos e outras contaminações que afetam os textos das páginas contíguas. Como tal, talvez a visibilidade destes $p(r) o(b /) e m a s$ não esteja circunscrita apenas ao facto de lidarem sobretudo com imagens, implicando também o problema criado pelo acto de intromissão que parcialmente oculta e extravasa o espaço onde se instalam.

\section{Montagem}

Deux fonctions sont généralement reconnues au montage: l'une concerne la lisibilité, l'autre la créativité du film. La première, parce qu'en relève la narration, est réputée fondamentale, la seconde étant plutôt méconnue ou négligée, voir suspecte. [...] En somme le montage n'est pas seulement justiciable de la représentation réglée sur un monde cohérent et unitaire. Il appartient de plein droit au fonctionnement du langage dans sa discontinuité constitutive conférant au film son caractère filmique. Unité et discontinuité caractérisent respectivement chacune des deux modalités du montage. Daniel Weyl, "Montage poétique"

A ideia de sequência, obtida através da ordenação de conjuntos de elementos, está presente na definição do esquema de composição do livro, como já foi referido. Essa ordenação não resulta apenas da fixação das folhas impressas numa determinada posição, devendo-se também à adopção de numerações seriais, à construção de articulações narrativas visuais e à introdução de outro tipo de padrões de repetição que estabelecem continuidades ao longo dos fragmentos que constituem o livro. No entanto, essas sequências estão sempre em tensão disruptiva, tanto ao nível das secções, como dos poemas, páginas, linhas, palavras e até das letras. Deste modo, vão-se acumulando leituras suspensas pela sucessão de interrupções que expõem desvios para outras hipóteses 
combinatórias. O processo de escolha também envolve outras tensões, nomeadamente quando numa mesma página de texto a eleição de hipóteses de leitura não oblitera momentaneamente as restantes e também quando num texto cujas variações ocupam mais do que uma página se torna difícil compará-las em simultâneo. Como tal, a dualidade entre sequência e interrupção identificada no processo de composição utilizado por António Aragão é afim à ideia de montagem expressa na citação em epígrafe, ou seja, dividindo-se entre unidade e descontinuidade.

O conjunto dos "P(r)o(bl)emas visíveis" reúne exemplos díspares de técnicas e formatos: três tiras com vinhetas que sugerem narrativas visuais, três impressos com formulários institucionais rasurados e uma composição com imagens e texto manuscrito. Rogério Barbosa da Silva, no artigo anteriormente citado, começa por considerar que a secção "P(r)o(bl)emas visíveis" "parece consistir numa espécie de síntese das anteriores" (Silva 2015: 41), o que não será alheio à eventual contaminação das leituras proporcionada pelo modo de assemblagem proposto pelo livro. No que diz respeito aos textos, a atenção de Barbosa da Silva centra-se na análise das conexões estabelecidas entre as tiras narrativas e as linguagens da banda-desenhada e da montagem cinematográfica (Silva 2015: 42). Vale a pena reparar também que determinadas sobreposições de poemas, para além de provocarem um intervalo no fluxo da leitura, amplificam as possibilidades de montagem através da relação visual que estabelecem com os seus pares, como no caso da "istória: eu dou, tu dás, nós damos, nós nós" em conjunto com o poema "que eu diga mais exactamente" (Aragão 1968: 7), que gera a leitura "eu dou exactamente [...]", "tu dás nós damos exactamente [...]" e "nós nós que eu diga mais exactamente [...]". Do mesmo modo, quando o poema "Câma Minicipal do unhal MÁGUAS - AVISO" se apõe ao texto "penso mais exactamente antes do meu retrato" (ARAGÃO 1968: 11), o processo de apropriação de material pré-existente utilizado no primeiro, através da rasura e acrescento de letras, parece encontrar ressonâncias no início visível do segundo:

\footnotetext{
volto-me um pouco no mês para a viol acção

das letras que flutuo e perco.

e cubro-me furiosamente com o pavor da cabeça

ou então retomo a roupa esquecida quando me mexes.
} 
e pelo negativo das palavras onde me

sento uso-me sobre o gosto e regresso:

Esta transcrição do texto de Aragão pertence ao conjunto "P(r)o(bl)emas", que, de acordo com António Preto, reúne "onze problemas linguísticos", onde o poeta "explora a ambiguidade dos enunciados verbais de modo a permitir a ampliação do campo semântico desses enunciados" (Preto 2005: 180-182). Um dos instrumentos para essa exploração, de forma a criar um "campo aberto de possibilidades" (Aragão 1965: 55), é, como tem vindo a ser demonstrado, a estratégia da montagem, enquanto tensão entre sequência e interrupção. Neste âmbito, é importante mencionar ainda dois exemplos. O primeiro diz respeito ao modo como o esquema gráfico desta secção apresenta características homogéneas (poemas numerados e sem título, que têm um alinhamento vertical preferencial à esquerda e a mesma margem superior no início de cada texto, sendo constituídos por estrofes de linhas variáveis, com letra minúscula) que são entrecortadas por pequenas alterações, como a inscrição de séries de palavras dentro de rectângulos (poema 2), a utilização generalizada de maiúsculas (poema 7), a reconfiguração da mancha de texto adoptando uma silhueta quadrangular em negrito (8) e a introdução de títulos (poema 10). Por outro lado, o conteúdo heterogéneo dos vários textos tece variações sobre elementos comuns, como nos modos de imiscuição entre a primeira e a segunda pessoa do singular: "desarrumo-te o meu perfil" (poema 1), "calo-me o teu ombro" (poema 2), "cor de folhearme as tuas mãos", "cresce-me o/ inexplicável do teu inacabar-me", "tu: quando me dói o lápis no/ pescoço mais exactamente" (poema 3), "jogo o teu perfil no totobola" (poema 5), "ah o amável preço da minha fotografia no teu/ retrato:" (poema 11).

Estas variações destacam-se, cruzam-se e geram novas interferências, enquanto chamam a atenção para as operações implicadas no processo de leitura (juntar, separar, dobrar, desdobrar, variar, seleccionar, memorizar, apagar, copiar, comparar, ...) em exercícios que testam as possibilidades da legibilidade do texto e do livro. 


\section{Colagem}

La citation tente de reproduire dans l'écriture une passion de lecture, de retrouver l'instantanée fulgurance de la sollicitation, car c'est bien lecture solliciteuse et excitante, qui produit la citation. La citation répète, elle fait retenir la lecture dans l'écriture: c'est qu'en vérité lecture et écriture ne sont qu'une seule et même chose, la pratique du texte qui est pratique du papier. La citation est la forme originelle de toutes les pratiques du papier, le découper-coller, et c'est un jeu d'enfant. Antoine Compagnon, La seconde main ou le travail de citation

Nas designações dos dois conjuntos de textos que estão por abordar, " $\mathrm{P}(\mathrm{r}) \mathrm{o}(\mathrm{bl})$ emas encontrados em livros", "P(r)o(bl)emas encontrados em jornais", António Aragão indicia a utilização da técnica da colagem, explicitando-a depois formalmente nos próprios poemas através da referenciação das fontes bibliográficas (Arte Portuguesa - As Artes Decorativas, Gramática de Língua Portuguesa e as Obras Completas de Luís de Camões) e da reprodução da imagem dos fragmentos de palavras recortadas de jornais, embora neste caso os nomes dos periódicos não tenham sido mencionados.

Os textos encontrados em livros ocupam sempre duas páginas, respectivamente a frente e o verso da mesma folha, não sendo possível adivinhar no início da leitura exactamente onde terá sido encontrado o poema. O leitor é também confrontado com a necessidade de manipular a página na presença de outros elementos paratextuais, como notas de rodapé e observações, que remetem para a ideia de interrupção através da inserção de novos fragmentos. Aragão continua a explorar linguagens poéticas semelhantes às utilizadas na secção " $\mathrm{P}(\mathrm{r}) \mathrm{o}(\mathrm{bl})$ emas", enquadrando-se entre os exercícios de permutações sintáticas e as combinações de imagens surrealizantes. Verifica-se, no entanto, que os elementos paratextuais, que convencionalmente contribuem para clarificar a comunicação, são utilizados neste caso para potenciar a ambiguidade semântica.

Retomando as palavras de Antoine Compagnon em epígrafe, a reprodução do prazer da leitura inerente a cada citação é trabalhada por António Aragão enquanto jogo que procura subverter as regras que se esforçam por conduzir os textos a leituras inequívocas. $E$ há determinados poemas que podem também ser entendidos como exemplos que demonstram as regras desse jogo perante o leitor, nomeadamente os que integram o conjunto " $\mathrm{P}(\mathrm{r}) \mathrm{o}(\mathrm{bl})$ emas encontrados em jornais". 
Esta secção apresenta duas colagens que formam constelações com letras e palavras de imprensa, de vários tamanhos e formatos, com uma silhueta negra sobre um fundo cinzento que corresponde ao papel recortado do jornal. A primeira página destas colagens tem uma dimensão menor que a sucessora, sendo possível observar-se parcialmente a maior quando estão sobrepostas. O sentido de leitura proposto é transversal em relação ao que existe nas restantes seç̧ões (excepto no caso de dois poemas visíveis). Cada uma destas colagens apresenta um texto que aparenta funcionar como uma transcrição que a duplica através de uma variação, porque não há correspondência integral entre as palavras que ambos utilizam. A impossibilidade de ler em simultâneo a colagem e o seu duplo obriga a mais um movimento de vai e vem entre folhas do livro para descobrir afinidades, articulações e desvios, instalando a suspeita de que o trabalho da escrita, exemplificado pela colagem, e o trabalho da leitura, incorporado pelo seu duplo transcrito, existem apenas em planos distintos e paralelos, que embora se sobreponham, apenas se cruzam no infinito.

\section{Colar em caso de emergência}

Des nombreuses oeuvres contemporaines nous mettent en situation de suspens, devant ou au coeur de constellations dont nous pressentons une possible configuration.ll nous appartient alors de faire notre propre collage, aussi intime que fugitif. [...] II ne s'agit plus de collage mais de liens ténus, immatériels, qui se font et se défont au gré des regards et des écoutes, entre mémoire collective et vécus singuliers. Le collage, alors, loin de la fixité, peut retrouver sa dynamique originelle et nous entraîner dans le monde des possibles. Jean-Louis Flecniakoska, "Collage et dispersion"

No texto em epígrafe, datado de 2000, Jean-Louis Flecniakoska fala do modo como a colagem é utilizada pela arte contemporânea, preferindo explorar as ligações ténues, móveis e permutáveis, em vez do modelo rígido que justapõe elementos fixos utilizado pelas vanguardas do início do séc. XX. Regressando ao artigo "Intervenção e Movimento", de António Aragão, é possível perceber que esse tipo de mobilidade também lhe interessa, nomeadamente através da referência aos mobiles de Alexander Calder (Aragão 1965: 55). No que diz respeito ao entendimento do livro, o poeta também recorre a exemplos de 
autores que investigaram sobre as possibilidades de compor um livro que, por um lado, pudesse ser construído como um monumento cujos elementos se movimentam livremente (Scherer 1957: 56-57), como defendia Mallarmé, e, por outro lado, pudesse funcionar como uma máquina de fabricar poemas, como propôs Raymond Queneau na introdução ao livro Cent Mille Milliards de Poèmes, publicado em 1961.

Ora, o livro Mais Exactamente $P(r) o(b /) e m a s$ não tem folhas libertas de qualquer constrangimento de encadernação, nem foi concebido com um engenho capaz de produzir mecanicamente diferentes combinações, como conseguiu Raymond Queneau. Como tal, a obra de Aragão, apesar de explorar as potencialidades virtuais de colagens fixas, experimenta também as possibilidades espaciais de um livro composto como uma assemblagem com sequências de elementos que se interrompem e contaminam, num esforço contínuo de ultrapassar os limites do rigor combinatório da linguagem, da poesia e do livro, entendidos como objectos, mais exactamente.

\section{Bibliografia}

Aragão, António (1965), "Intervenção e Movimento", Jornal do Fundão, Suplemento, 24 de Janeiro (consultado em Hatherly, Ana/ Melo e Castro, E. M. de (orgs) (1981), Po.Ex. Textos teóricos e documentos da Poesia Experimental Portuguesa, Lisboa, Moraes Editores, 51-56). -- (1968), Mais Exactamente P(r)o(bl)emas, Funchal, s.n.

Cardoso, Catarina Figueiredo (2015), “«'Ler' o poema é simplesmente dobrar e desdobrar» ['To read' the poem is simply to fold and unfold]. Artist's books by António Aragão", Cibertextualidades, N. 07, Edições Universidade Fernando Pessoa: 109-125.

Compagnon, Antoine (1979), La seconde main ou le travail de citation, Paris, Éditions du Seuil. 
Flecniakoska, Jean-Louis (2000), "Collage et dispersion" in Le collage et après, Paris, L'Harmattan: 81-91.

Litzler, Pierre (2000), "Architecture et Poétique de L'assemblage", in Le collage et après, Paris, L'Harmattan: 21-51.

Perloff, Marjorie (1998), "Collage and Poetry", in Encyclopedia of Aesthetics, New York, Oxford U Press, Vol 1: 384-87.

Preto, António Manuel João (2005), A Poesia Experimental Portuguesa, Lisboa, s.n. [Tese de mestrado].

Queneau, Raymond (2009), "Cent Mille Milliards de Poèmes: Mode d'Emploi”, in Anthologie de l'OuLiPo, Paris, Gallimard [1961].

Scherer, Jacques (1957), Le "Livre" de Mallarmé, Paris, Gallimard.

Silva, Rogério Barbosa da (2015), "António Aragão, ou a liberdade de invenção",Cibertextualidades, N.o 07, Edições Universidade Fernando Pessoa: 33-43.

Waldman, Diane (1992), Collage, assemblage, and the found object, New York, Harry M. Abrams.

Weyl, Daniel (2000), “Montage poétique”, in Le collage et après, Paris, L'Harmattan: 53-72.

Sara Lacerda Campino é licenciada em Arquitectura pelo IST-UTL. Em 2012, concluiu o mestrado em Estudos Portugueses, variante Estudos Literários, com a dissertação "O Experimentalismo na Obra de Alexandre O'Neill", na FCSH-UNL. Prepara o doutoramento na mesma faculdade, integrada no IELT desde 2013, continuando a investigação sobre as poéticas experimentais portuguesas da 2. a metade do séc. XX. 